\title{
Improving Student Preparedness and Retention-Perceptions of Staff at Two Universities
}

\author{
David Marr ${ }^{1}$, Camilla Nicoll ${ }^{1}$, Kathryn von $\operatorname{Treuer}^{1}$, Christina Kolar $^{1} \&$ Josephine Palermo $^{1}$ \\ ${ }^{1}$ School of Psychology, Deakin University, Australia \\ Correspondence: Associate Professor Kathryn von Treuer, School of Psychology, Deakin University, Australia. \\ Tel: 61-3-9244-6554. E-mail: kathryn.vontreuer@deakin.edu.au
}

Received: February 11, 2013 Accepted: March 12, 2013 Online Published: July 18, 2013

doi:10.5539/hes.v3n4p1 URL: http://dx.doi.org/10.5539/hes.v3n4p1

\begin{abstract}
In 2010 the Australian government provided funding under the Higher Education Participation and Partnerships Program (HEPPP) to assist universities to achieve a 20 percent participation rate for students from lower socioeconomic backgrounds. This funding has allowed universities the opportunity to implement projects towards this end. This study explores the reactions of staff employed in devolving HEPPP projects within Deakin University (DU) and Southern Cross University (SCU). Both universities have a diverse student body, with participation by regional and low socioeconomic status (SES) students at higher proportions than the national higher education average. DU has used its HEPPP funds to establish the Deakin University Participation and Partnerships Program (DUPPP), which comprises community, school and technical/vocational education and training partnerships, embedded academic skills programs, and inclusive support programs. In contrast, SCU, through its i-OnTrack project, is developing a tracking system that will follow cohorts of students coming from diverse backgrounds in order to identify those factors in their life that either impede or boost academic excellence. Key informant interviews of academic staff at both these universities $(\mathrm{N}=18)$ were thematically analyzed and compared. Our recommendations for institutional practice across Australia arising from this analysis include: the need to maintain appropriate resourcing for academic staff (especially for casual tutors) to support the kinds of programs that make a difference, to commence intervention programs early at secondary school and prior to the students entering university, and for intervention programs to target all students in order to capture any students who may not be obviously at risk.
\end{abstract}

Keywords: attrition, low socioeconomic status students, university case study, preparedness, student retention

\section{Introduction}

Higher education is frequently perceived as an opportunity to improve one's life and plays a fundamental role in improving the SES of individuals, their families and the community (Valentine et al., 2009). However, the dream of university education is not equally realised for everyone. For example, the enrolment and completion patterns of lower SES students do not reflect this ideal. Student attrition is high among this specific cohort. Student attrition is defined as reduced student enrolment due to university transfers or 'dropouts', and has been a long-standing problem for universities around the world (Willcoxson, Cotter \& Joy, 2011).

Prior to the 1970s, student attrition was considered confirmation of an institution's demanding curriculum (Thelin, 2010). However, the financial losses incurred due to student attrition started to affect educational institutions. In addition, it resulted in social costs to individuals and society. Consequently, academic leaders were urged to review their institutional data, administrative procedures and institutional culture to understand better why so many students failed to complete their courses (ACT Inc., 2010; Armstrong, Campbell \& Brogan, 2009; Conner, 2009; Hawley \& Harris, 2005; Lillibridge, 2008; Schurr, Ruble, Palomba, \& Pickerill, 1997).

The development of student tracking and prediction methodologies has been followed by the extensive implementation of intervention programs (Bashford, 2008; Blanc, DeBuhr \& Martin, 1983), with most strategies designed to assist those students identified as being at risk of dropping out (Cabrera et al., 2006). However, there is a lack of a comprehensive tested theory of student attrition and retention (Cabrera et al., 2006; Valentine et al., 2009). This deficit has created considerable difficulties not only for comparing studies, but also for advising the best approach for maximum impact and value for money. There is also a significant gap in the knowledge concerning the impact that these interventions have on student success. 
Previous research in student tracking, retention, attrition, and success appears to be fraught with methodological issues such as the lack of comparison groups and longitudinal data collection (Valentine et al., 2009). Consequently, there is no directly informed robust approach being developed to improve student retention from target groups. In Australia, government funding provided through the Higher Education Participation and Partnerships Program (HEPPP) is hoped to increase the proportion of students from lower SES backgrounds accessing higher education. With few robust empirical studies existing, case studies provide one approach to exploring the efficacy of such programs. This paper reports on the early perceptions of staff devolving HEPPP at two universities.

\subsection{The Background Contexts of the Two Universities}

HEPPP funding has enabled universities to introduce programs to improve access and the sustainability of undergraduate enrolments from students from low SES backgrounds. Universities have approached the utilisation of these funds in various ways. The two universities selected for this comparative study have participation rates well above their respective state and national averages. These may loosely be classified as under-prepared student cohorts; namely, those from low SES backgrounds, regional and rural areas, and first-in-family backgrounds.

Two Australian universities-Deakin University (DU) and Southern Cross University (SCU) have adopted processes to track students through the student life cycle in order to better understand the factors that lead to students leaving prematurely, including identifying student characteristics that may indicate that they are more "at risk". DU established 12 strategies, which encompass 24 interventions. These strategies are:

- Strategy 1: Partnerships with under-represented schools - includes six intervention programs;

- Strategy 2: Partnerships with other educational providers;

- Strategy 3: Partnerships with communities - includes four intervention programs;

- Strategy 4: Inclusive entry processes - aims at making application, selection and enrolment processes more equitable and accessible for low SES students; includes two intervention programs;

- Strategy 5: Reducing financial, transport and accommodation barriers-includes two intervention programs;

- Strategy 6: Removing barriers to access facilities, technology and information-includes two intervention programs;

- Strategy 7: Inclusive support programs - aims to provide better support services for low SES students;

- Strategy 8: Cohort targeted support programs—offering peer mentoring programs;

- Strategy 10: Supporting graduate outcomes-includes three intervention programs concerned with embedding academic skills, paid work placements and bursaries/scholarships for low SES students;

- Strategy 11: Curriculum development—aims to identify and improve inclusive teaching and learning practices; and

- Strategy 12: Innovation fund - an evaluation model will be developed to evaluate the impact of these strategies on the participation and success of low SES students.

In 2012 SCU had 20 HEPPP projects, the two most relevant to this study being: (1) examining the sources of high-achieving low SES students; and (2) the i-OnTrack project, an online diagnostic tool that aims to target students who are at risk of withdrawal or failure. Appendix A provides further information on some of these interventions.

The significant differences between the two institutions are that DU is predominantly a large metropolitan university located in Victoria, while SCU is a small regional university located in northern New South Wales. Both universities currently have Commonwealth-funded HEPPP projects particularly concerned with identifying and affecting the attrition rates of under-prepared students.

DU's Diverse Student Cohort Tracking Committee (DSCTC) and SCU's i-OnTrack Committee have responsibility for the implementation of their respective HEPPP projects (known as the Deakin University Participation and Partnership Program [DUPPP] at DU). A number of the members of these committees participated in the interviews for this qualitative study.

The aim of this study was to collect information from both universities to gain a better understanding of their intervention programs, their philosophical approaches to attrition, and the cohort tracking systems they are using 
to identify, support, and track at-risk student cohorts. The outcomes from this case study can inform approaches and policies related to increasing the access, participation, and retention of low SES, low income, and academically under-prepared students, as well as assisting in the modification and improvement of current data warehousing and tracking systems.

\section{Method}

\subsection{Participant (Subject) Characteristics}

Eighteen participants ( 8 male and 10 female) were recruited from DU's DSCTC ( $n=12)$ and SCU's i-OnTrack Committee $(n=6)$ via an email invitation. They were invited to participate in the study because they were key informants from multidisciplinary teams comprising teaching and learning academics and data warehousing and analysis experts. In addition, end users within the faculties, schools and equity and planning units involved in the various interventions or tracking projects were also interviewed.

Table 1. Number of interview participants by institution

\begin{tabular}{lccccc}
\hline \multirow{2}{*}{ University/campus } & \multicolumn{2}{c}{ Academic } & \multicolumn{2}{c}{ Professional } & \multirow{2}{*}{ Total } \\
\cline { 2 - 5 } & Male & Female & Male & Female & 12 \\
\hline Deakin University & 1 & 2 & 5 & 4 & 1 \\
Sothern Cross University & 1 & 3 & 1 & 1 & 6 \\
\hline
\end{tabular}

Table 1 shows the breakdown of the participants into academic/professional and male/female groups by institution or campus location.

\subsection{Measures}

A 16-item semi-structured interview schedule was developed, and interviews were conducted across both universities (see Table 1). The interview questions clustered around issues for the people, processes and technologies required to monitor groups of students as they entered the higher education system and during their subsequent progression. Examples of sample questions are, 'How do you assess academic and/or social preparedness?' and 'What new technologies could assist you in tracking?'

\subsection{Procedure}

Face-to-face interviews of approximately one hour's duration were held with each participant. Interview participation was completely voluntary and consent was obtained at the time of interview. Participants were encouraged to discuss their experiences and opinions in relation to university intervention projects, structures, policies and governance in which they were involved rather simply responding to the questions provided (a semi-structured approach). Interviews were audio-recorded and later transcribed. The transcripts were returned to the participants within six to eight weeks, giving them the opportunity to verify the transcripts' accuracy.

The qualitative analysis of the interview transcripts was adapted from Braun and Clarke (2006). They defined two valid thematic analysis methods: (1) developing the themes as the analysis is being undertaken, with these themes being grouped later into broader categories and (2) developing the themes in advance of the analysis and coding the transcripts according to these predefined themes. The latter method allows additional themes to be added while the analysis is being undertaken and for modifying some of the prescribed themes when (or if) required. The interview transcripts were thematically coded using the second method due to the exploratory nature of this study. Initial thematic coding was done by one coder, with a second verifying the codes. Any discrepancies were discussed and a decision then made as to the final code. There was an initial agreement of over $95 \%$ between the themes identified by the first and second coder. NVivo 10 software was used for the final thematic analysis.

\section{Results}

Our findings revealed five main themes around student retention which emerged from the data. These were: preparedness, at-risk students, intervention types, governance and technology. These five themes were made up of several sub-themes, presented in Tables 2-6. Quotes are verbatim comments from participants (those prefixed with a 'D' are from DU staff; those prefixed with 'S' are from SCU staff). 


\subsection{Preparedness and Readiness}

Student preparedness and readiness was a commonly mentioned theme, and its sub-themes are presented in Table 2 .

Table 2. Sub-themes of student preparedness/readiness which emerged at DU and SCU

\begin{tabular}{ll}
\hline Deakin University & Southern Cross University \\
\hline Academic & Academic \\
ATAR/grade point average & ATAR/grade point average \\
Goals and values & Goals and values \\
Career and employment & Career and employment \\
Partnering with schools/TAFEs & Numeracy \\
Social & Partnering with schools/TAFEs \\
University assessments & Social \\
Unpreparedness/low support & University assessments \\
& Unpreparedness/low support \\
\hline
\end{tabular}

The participants from both DU and SCU stressed lack of support as having a huge effect on students entering university. They believed that students might lack engagement when they feel isolated, overwhelmed or inconsequential. One DU interviewee made the following comment:

'One of the mentees ... was saying, "I went to a medium-size school but this [DU] is scary as hell". And I asked, "what is the big difference", and she said, "no one is hounding you about your assignments, nobody is checking up on you, nobody cares about you".' [D01]

Similarly, an SCU interviewee relayed this experience:

'I went to ... university from [a small town] high [school], where there [were] 1,100 students in the school, 3,000 in the town. And in my first lecture in psychology I had 1,500 students in the ... auditorium and it was like, "ahhh", it was the saddest year of my whole life ... nobody knew who I was, nobody cared.' [S46]

In addition, simple matters of which the institution might not have been aware or responsible - and had few ways of controlling - could have caused students to feel that they were not coping or not fitting into university life:

'Eighty-five per cent of those students who dropped out in the first year ... [were] because of events that were short term and could be resolved quite easily ... things like transport, the house ... like the kids got sick.' [D13]

Although there were many similarities between the universities, numeracy seemed to be a concern only at SCU. Staff noted that students had high levels of mathematics-related anxiety, and that it was imperative to improve student numeracy levels, particularly since so many students were studying to be teachers and thus would soon be responsible for teaching mathematics themselves. In fields such as nursing, numeracy shortcomings were particularly concerning:

'Some of the nursing students, they get it wrong, because they get sort of, instead of 0.05 , they have 0.5 and they have said, "but it is only one space from the dot, what does that matter?" Well actually if you are administering it, a dose of some medicine to a baby, based on their body weight, it actually matters a fair bit. The difference between 0.05 and 0.5 can kill them.' [S51]

SCU has employed a Mathematics Support Officer dedicated solely to numeracy. However, participants noted that funding and resources were insufficient to combat effectively students' numeracy shortcomings. Participants speculated that this problem stemmed from the secondary school system:

'They could get an ATAR [Australian Tertiary Admission Rank] of 99 studying no maths and so they would get this ATAR of 99, after studying no maths come into physiotherapy and the first thing they are confronted with is the basic maths in order to do mechanics.' [S50] 


\subsection{At-Risk Students}

The at-risk theme encapsulates targeting students with particular characteristics or circumstances that might cause unpreparedness and ultimately attrition. Table 3 presents the sub-themes of these at-risk students.

Table 3. Sub-themes of 'at-risk' which emerged at DU and SCU

\begin{tabular}{ll}
\hline Deakin University & Southern Cross University \\
\hline Aboriginal and Torres Strait Island students & Aboriginal and Torres Strait Island students \\
Alternative pathways to university & Alternative pathways to university \\
Community & Community \\
First in family to attend university & First in family to attend university \\
International & International \\
IT issues & IT issues \\
Low SES & Low SES \\
Mature age & Mature age \\
Non-English speaking background & Personal factors \\
Personal factors & Postgraduate entry \\
Postgraduate entry & Rural/isolated students \\
Rural/isolated students & School leavers \\
School leavers & Study mode (on/off campus) \\
Study mode (on/off campus) & Travel/location \\
Travel/location & \\
\hline
\end{tabular}

Despite the many sub-themes identified, a common theme at both DU and SCU was that actually identifying at-risk students was challenging. Rather than purely identifying at-risk students and targeting intervention programs at these students, it was considered preferable for the two universities to implement an inclusive approach that addressed the issues encountered by the at-risk group. One DU interviewee made the following comment:

'It is a bit like heart attacks ... the high-risk people are much more likely to have one, but they are relatively small in numbers so the bulk of heart attacks happen from the low-risk population. It is harder to predict, so we actually need those universal preventions to try to ... stop people falling through the cracks ... because often they are not the identified high-risk group.' [D01]

One way that institutions have dealt with at-risk students is by offering several alternative pathways for degree program entry (see Table 3). These pathways can prepare students academically and socially for the kind of experience they might encounter once they commence undergraduate study:

'To start thinking about a university as another stepping stone ... that each step was a valuable experience to getting you there.' [D09]

For example, DU has an articulation arrangement with the Melbourne Institute of Business and Technology (MIBT, see Appendix A) whereby students commence studies with a private provider and obtain credit for studies undertaken towards a business degree. This creates a viable degree pathway to a degree at DU for low SES students. In addition, DU is exploring ways to help struggling students return to the TAFE system.

'One of the DUPPP [Deakin University Participation and Partnership Program] projects is to try to identify, if a student doesn't succeed at university, can we create, almost a backward credit scenario, where they can actually go back to one of our TAFE partners ... and they might come back to Deakin or they might not.' [D13]

SCU also offers a number of alternative pathways into their undergraduate courses. Preparation for Success is an enabling course that provides basic study skills and develops research and writing skills in the arts, business or sciences. Alternatively, SCU offers two-year Associate Degree courses in allied health, the arts and business for 
students who could not otherwise meet Bachelor degree entry requirements. Students complete a TAFE Certificate IV as part of their first year of allied health and arts courses, and are thus give several exit points if they do not choose to pursue undergraduate studies. As one interviewee remarked, 'this gives a more supportive environment that will give them more confidence in doing university-level study'. [S38]

Some universities, such as SCU, act as 'feeder' institutions. They can provide access to tertiary studies for low-performing or underprepared students, giving them basic learning and content skills that will allow them to transfer to higher-entry courses elsewhere. From an institutional perspective, this would be characterised as attrition; however, in these cases, it is 'good' attrition, since these students are progressing along their educational path:

'You have got to fail to succeed ... [students from] more privileged backgrounds ... don't know how to fail. And failure is not an option to them; "you have to fail first, to try and achieve anything" philosophy. Some regional universities act as feeder education providers, so they appear to be attrition but it is "planned". They can play an important preparation role.' [S42]

Regarding at-risk students, there was a difference between DU and SCU: DU recognised the importance of targeting students from non-English speaking backgrounds. One of Deakin's DUPPP projects targeted those from a non-English speaking background by implementing a mandatory English and literacy screen at enrolment. The purpose of this was to identify students who might need help and to refer them to relevant support services. $\mathrm{SCU}$ is yet to implement this sort of screening test.

Sometimes the circumstances that lead students to being at risk might be very basic. One participant stated the following:

'Students have real issues like poor diets, don't know how to cook, poor finances [and] therefore cannot afford text books, access to communication, broadband etc.' [S38]

Programmes addressing at-risk student needs should embrace many aspects of their higher education.

\subsection{Interventions}

The third theme that emerged from the data was interventions. Both universities implemented multiple strategies and interventions because of HEPPP funding (for specific examples see Appendix A. The sub-themes that emerged from this analysis are presented in Table 4.

Table 4. Sub-themes of intervention which emerged at DU and SCU

\begin{tabular}{ll}
\hline Deakin University & Southern Cross University \\
\hline Communication post-alert trigger & Communication post-alert trigger \\
Electronic communication & Electronic communication \\
Embedding academic skills & Embedding academic skills \\
Engaging parents/students & Engaging parents/students \\
Financial support & Financial support \\
Generic & Generic \\
Individual assistance & Individual assistance \\
Peers and mentoring & Peers and mentoring \\
Orientation program & Orientation program \\
Scholarships & Staff feedback \\
Staff feedback & Transition (in and out) \\
Transition (in and out) & Workplace relevance \\
Workplace relevance & \\
\hline
\end{tabular}

One of the issues facing DU students was their lack of referencing skills. Accordingly, one intervention involved embedding academic skills into the standard first year curriculum across all courses. This was designed to assist underprepared students with the necessary skills for academic success. Of course, they could be underprepared 
for various reasons: coming from a rural or regional area, transitioning from a vocational training background or being mature age and perhaps not having written an essay since high school. However, not all new students from these cohorts would have difficulty with referencing; hence, a better approach would be to target the issue of poor referencing skills rather than a particular cohort. DU is taking a proactive approach to referencing skills and embedding referencing into the curriculum rather than running a service in which students can choose to participate.

Similarly, at SCU, despite the first year mentoring program being available to all students, the equity unit's participation analysis showed that students with low SES and from regional areas were participating of their own volition. As one SCU interviewee commented, 'monitor cohorts, but don't target them'. [S50]

Another strong view raised in the interviews was the need for the institution to adapt to the changing needs of its diverse student body. For past generations, strategies focused on ways to encourage and support these students to fit the 'norms' represented within each institution; these were mostly middle class and, on the whole, privileged. With a push in Australia for greater access and participation from low SES students, institution administrators need to reconsider how they can engage these students. One way to achieve this is by thinking more laterally and adopt policies and practices that meet this generation of students' differing needs. One DU interviewee made this point:

'They [students] need a really good reason to come on to campus, and often, going to the lectures isn't a good enough reason. Especially if you can then view it online ... we really need to be very flexible.' [D05]

Another interviewee commented that adjusting assessment as well as curricula might be considered to meet current student needs:

'How draconian do we have to be ..." You will be deducted 10 points for every minute you are late!" It is ridiculous. It is like a penal servitude system. I don't know why it has to be that way.' [D28]

A SCU academic interviewee made this comment:

'The new generation expects everything to be flexible. We are kind of being adversely affected by the very thing that we are promoting ... flexibility. Better outcome for the individual; poorer outcome for the institution based on the current indicators that we are using.' [S38]

The importance of orientation programs to student attrition also emerged within the data. One anecdote from a DU academic seemed to resonate with these findings:

'I went to a freshers' camp ... there were a hundred of us ... sitting up at the café every single day, and when I left Honours four years later, there were still 30 or 40 of us having lunch together every day ... and out of that group only one of us failed first year.' [D01]

DU's u.life programme was piloted in 2011 and was aimed at Year 9 school students with the intention of demystifying university and tertiary study. In 2012, the Widening Horizons programme was designed to build on u.life by opening up different pathways for students who are also young parents:

'I feel quite strongly about the need to engage with low SES communities at a very early age. One Year 9 girl ... was going to work in childcare. On her follow-up questionnaire ... she was talking about early childhood development. She picked up some of that insider language.' [D02]

Participants spoke often about making the notion of university and tertiary studies more accessible, relevant and meaningful in a language that today's students understand.

The importance of peer mentoring in relation to attrition was discussed at both universities:

'[There are] stories of students who have been so full of praise for their mentor ... [saying] "they helped me and I would have left if it wasn't for them".' [S42]

Finally, some differences were noted between DU and SCU. Firstly, only DU participants mentioned the importance of scholarships. Secondly, regarding the maturity of the HEPPP projects, DU projects appeared to be slightly more entrenched and better understood than the less mature SCU equivalents. The purpose of the projects and their interrelationships were better communicated at DU, perhaps due to their complex nature. The longer period over which the projects had been running also allowed a stronger and more mature communication strategy to be developed than was observed at SCU.

\subsection{Responsibility and Governance}

This fourth theme involved all aspects related to leaders and those responsible for interventions and other university issues. Table 5 presents the sub-themes that emerged. 
Table 5. Sub-themes of responsibility and governance which emerged at DU and SCU

\begin{tabular}{ll}
\hline Deakin University & Southern Cross University \\
\hline Attrition & Attrition \\
Curriculum issues & Curriculum issues \\
Diagnostic tools & Diagnostic tools \\
Funding & Funding \\
Philosophy and culture & Philosophy and culture \\
Targeting issues & Targeting issues \\
Tracking issues & Tracking issues \\
University staff & University staff \\
\hline
\end{tabular}

Culture change could be necessary to improve attrition rates. If students are continually dropping out, universities and colleges might need to re-evaluate their current standards and shift towards change:

'It is also about a combination of a shifting culture. About going," well hold on, we are talking about the long term, not the short term". What we actually want to know is three years down the track.' [D15]

A common theme present in the interviews was the need for the institutions to be more cognisant of students' needs and listen to the students' voices. The universities would thus be prepared to change their culture and perhaps philosophy to be more 'student-centred' and inclusive of the different cultures represented in the student body:

'Actually [we've stopped] listening to the students' voice ... and giving them a voice ... is really valuable. The multiple ways in which we describe the same process ... we talk about credit transfer, advanced standing, articulation ... and all of that must be incredibly confusing. So it is really a matter for the whole institution to be thinking about working collaboratively. We don't recognise that low SES isn't just a socio-economic status ... there are cultural differences as well ... those are actually rich, cultural experiences.' [S38]

There was considerable concern among several interviewees from both DU and SCU that higher education in Australia is not currently resourced adequately enough to allow academic staff to build these kinds of relationships. Tensions between teaching and research, promotion criteria biased towards producing a certain quantity of research papers and earning competitive grant income left little time for these meaningful teacher-student interactions that could assist students' transition to university. Some interviewees believed that the casualisation of teaching staff only added to this dilemma:

'The research indicates, and my experience indicates, [that] students benefit from contact with their teachers ... but we are not funded to give contact.' [D28]

'[If you want] better retention rates from low SES [students] ... and if you [want to] make a difference to students, it is in your own time. You don't get paid. With increased levels of casualisation, you get paid for the tutorial; you get paid for two hours of consultation. If you spend another hour or two with students, because they are facing a crisis, [then] that is [in] your [own] time ... to me, those two things are in stark contrast.' [S39]

'Being an expert is important, but you need to be able to relate, show empathy and be human. That's missing in the professional teaching and learning courses. Changes over the past 15 years [include] increased class sizes, more casual teaching staff, a more diverse student population. These leave the teacher-student relationship vulnerable.' [S39]

Cohort tracking issues were also raised by both DU and SCU staff. Although the perceived value of tracking student cohorts varied a little, both groups acknowledged that more than raw numbers should be collected: 'to focus on cohort measures ... because you want the complete picture about the cohort' [D22] was one example from DU, and another was, 'what we are also trying to do is also capture the stories rather than just collect the data. We actually want the stories from the people' [D13]. A third staff member made this comment:

'What do I want to do with that data? What do I need it for, and also ... how is it collected and how is it connected to what I do? Kind of collecting data just for the sake of it ... I think to me it is much more about 
the dialogue with students.' [S39]

\subsection{Technology}

Technology was the fifth theme and was considered of utmost importance to student retention. Table 6 presents the sub-themes that emerged from the data.

Table 6. Sub-themes of technology which emerged at DU and SCU

\begin{tabular}{ll}
\hline Deakin University & Southern Cross University \\
\hline Data warehouse repository & Data warehouse repository \\
Emerging technologies & Emerging technologies \\
External data sources & External data sources \\
Predictive modeling & Predictive modeling \\
Use of online applications & Use of online applications \\
\hline
\end{tabular}

With ever-increasing opportunities to implement technological solutions, it is not surprising that institutions such as DU and SCU are exploring greater use of information and communications technology to assist in detecting and supporting at-risk students. DU has begun implementing alert triggers based on usage of the Blackboard online learning management system and grades. These triggers provide students with an on-demand, objective and non-human assessment of their own performance against an anonymous summary of their peers. Knowing where they stand relative to their peers is intended to motivate them to seek and accept academic support. The tool is explained as follows:

'It monitors DSO [Deakin Studies Online] at linkage ... and you get an SMS. "Hi [name], how is your first two weeks going?" Nothing more. And it only goes to those students who haven't logged onto DSO. Or haven't been in class. So it is a gentler version and it builds up to phone calls, etc. So that is operating through university as a general way of trying to find individuals who are not engaging ... successfully.' [D01]

\section{Discussion}

Changes in government policy to increase participation by low SES applicants will only be successful if institutions provide relevant programs to address the needs of at-risk students. In Australia, increased funding has recently been made available to universities to enable them to run programs to increase the participation of students from low SES backgrounds. Limited evaluations of these interventions have been conducted due to the recent implementation of many of these programs. Preliminary evaluations are useful to ensure that programs are on track and provide value for money. The aim of this study was to collect information from both DU and SCU to gain a better understanding of their current intervention programs, their philosophical approaches to attrition, and the cohort tracking systems they are using to identify, support, and track at-risk student cohorts. Thematic analysis revealed that five main themes emerged from the data: preparedness, at-risk students, intervention types, responsibility and governance, and technology. Comments were made by the participants in relation to the perceived usefulness of their interventions, but these were limited due to the early stage of these programs.

This study has demonstrated that there are many similarities and some differences between the perceptions of the staff responsible for HEPPP at DU and SCU. These similarities may be attributable to a common progression in knowledge and science, which have been applied to the HEPPP projects at each university. In relation to student preparedness both universities were very aligned with respect to acknowledging the "culture shock" many students experience at the commencement of their course. Further, partnerships that universities have with secondary schools and TAFE institutes, goals, values, and social aspects were all raised as themes of under-preparedness. An emphasis on numeracy was only raised as an issue of under-preparedness by participants at SCU. Students from non-English speaking backgrounds were mentioned by DU participants, but not by participants from SCU.

Numerous aspects were mentioned that staff perceived placed students at risk. Further, there was a common understanding between the universities of the factors that may potentially categorise a student as being at risk. One more recent at-risk aspect is those students who are the first in their family to go to university. Often these "first-in-family" students receive less support from their families, have lower critical thinking skills, and are less 
inclined to socialise with their peers. Their high school experience was such that they spent little, if any, time talking with their teachers (Terenzini, Springer, Yaeger, Pascarella, \& Nora, 1996).

DU offered a larger number of interventions compared with SCU, and also offered a greater proportion of social integration strategies. This can be seen in Appendix A, which reveals that there are four supportive interventions for students at DU, outnumbering the sole supportive intervention (peer mentoring) at SCU. Differences were also noticed by the researchers, in that the interventions at DU seemed to be more embedded within the university setting. Supportive interventions, such as peer mentoring or the embedding of academic skills into first year curricula, were more frequently implemented at DU, however were implemented at both universities. Social interventions at universities have been well established as effective tools for increasing student retention (e.g., Cerezo, \& McWhirter, 2012; Putsche, Storrs, Lewis, \& Haylett, 2008); Robinson, \& Niemer, 2010) especially in the area of peer mentoring. According to Ramsey and Gorgol (2010), peer mentoring, used in conjunction with other strategies, provided improved opportunities for low-income students as a result of their participation in the Washington State Achievers Program. Orientation programs were also found to be integral to retention. Recent studies have begun to correlate retention with orientation programs (Ali \& Leeds, 2009; Mansfield, O’Leary \& Webb, 2011; McPherson, 2008; Smith, 2010; Starke, Harth \& Sirianni, 2001).

Governance and responsibility were important factors as the institution's ability to "listen to the student voice" and to provide a university culture that is able to respond via funding and philosophical culture were important aspects for decreasing attrition in students from low SES backgrounds. A study which recruited a high school sample found that hardened educational policies, reduced standards, reduced emphasis on accountability, and lack of student voice; contributed to increased attrition rates among minority students since they became hostile and felt that their efforts were under-valued at their educational institution (Smyth, 2006). The present study has replicated this result within a novel tertiary environment. Additionally, the usefulness of cohort tracking was challenged by some SCU staff members.

Technology was stated to be an important player in student attrition, and both universities utilized technology to target struggling students. Alas, past research has found that technological resources are linked to student retention (e.g., Butler, 2013; Heaton-Shrestha, May, \& Burke, 2009; Salazar, 2010), however in most cases past research has only examined technology as a means of improving communication and learning, the phenomenon of targeting at risk students which was examined in the present study is a new and interesting element in the technology and student retention relationship. Additionally, the university curriculum was also targeted as a means of intervention at DU, where referencing was added to first year curricula in order to increase student preparedness, which has also been found to assist with student retention rates in past literature (Taylor, 2005)

\subsection{Study Limitations}

In this study the data reported by staff provide an early snapshot of their opinions around at-risk students and the interventions undertaken at the two universities. The real impact of these initiatives will not be known without a more intensive study being undertaken over a much longer period, possibly also measuring student data, including outcome data. Each intervention could be measured against the theme specific to the target at-risk group. Despite the need for a more detailed study, the preliminary data does provide a basis for the following recommendations, discussed below.

\subsection{Implementation/Recommendations}

The staff perceptions advocated for intervention programs that targeted all students, in order to capture students who may not be obviously at risk. Therefore, parallel interventions would ideally target both at-risk student populations along with retention programs for students in general. This is consistent with the literature which has found both general interventions (e.g., Bai \& Pan, 2009; Sanchez-Leguelinel, 2008) and targeted interventions (e.g., Huett, Kalinowski, Moller \& Huett, 2008; Nichols, 2010) to be effective in reducing student attrition.

The findings also suggested that interventions should start as early as possible, depending on the type of intervention being observed. Orientation programs for high school students have historically focused on senior students more as a marketing exercise to attract the "brightest and best" to a particular institution. With government campaigns to increase participation from non-traditional student cohorts, orientation programs started to focus more on raising aspirations and providing programs that would allow these new cohorts to transition successfully. Both DU and SCU had orientation programs involving Year 9 secondary school students, but were considering targeting groups as young as Year 6 . However, the commencement of university programs during high school years, or earlier, does not feature in the existing literature. 
Further resources are needed to assist with institutional culture change. Institutional leaders need to take a more "student-centered" approach, one that listens to what current students say they need. Previous research which has adopted student-centered approaches towards learning has found favourable outcomes (e.g., Gibson, 2011; Hannum, Irvin, Lei \& Farmer, 2008). Leaders must also recognise the different cultures that a more diverse student population encapsulates and respond appropriately to students from these cultural backgrounds.

Appropriate resourcing is also important. Academic staff (especially casual tutors) ideally must be properly resourced or funded to support programs that make a difference.

Another emerging theme from the interviews was that having first year classes taught by casual academic staff may be a cheap alternative, but may also pose a risk in terms of providing under-prepared students with limited access to their regular tutors and lecturers. In this day and age, with the advancements in technology, universities have greater opportunities to be clever in the ways they interact with and support their students. Through alert triggers and targeted correspondence, students can receive positive feedback and useful advice and information in a friendly, $24 / 7$ format.

\subsection{Conclusion}

Both DU and SCU have adopted a range of actions and activities to raise the retention of students from lower SES backgrounds. These findings could be generalisable to other higher education systems who may be facing similar challenges. The outcomes from this case study will further inform approaches and policies related to increasing the access, participation and retention of low SES, low income, and academically under-prepared students, as well as assisting in the modification of current data warehousing and tracking systems. How successful these initiatives will be in increasing retention and completion rates is yet to be seen. This study has focused on the early stages of what will be a long process, and so far, reports positive findings. The efficacy of these initiatives will not be known without a more intensive longitudinal study being undertaken.

\section{References}

ACT Inc. (2010). What works in student retention? Fourth national survey. Community Colleges Report. Iowa City, IA: ACT, Inc.

Ali, R., \& Leeds, E. M. (2009). The impact of face-to-face orientation on online retention: A pilot study. Online Journal of Distance Learning Administration, 12.

Armstrong, S., Campbell, M., \& Brogan, M. (2009). Interventions to enhance the student experience of a first year law degree: What they really wanted. Preparing for tomorrow today: The first year experience as foundation: First Year in Higher Education Conference 2009, 29 June-1 July 2009, Townsville, Queensland.

Bashford, J. (2008). Using student tracking data from an institutional perspective. New Directions for Community Colleges, 143, 31-36. http://dx.doi.org/10.1002/cc.333

Blanc, R. A., DeBuhr, L. E., \& Martin, D. C. (1983).Breaking the attrition cycle: The effects of supplemental instruction on undergraduate performance and attrition. The Journal of Higher Education, 54, 80-90. http://dx.doi.org/10.2307/1981646

Braun, V., \& Clarke, V. (2006) Using thematic analysis in psychology. Qualitative Research in Psychology, 3, 77-101. http://dx.doi.org/10.1191/1478088706qp063oa

Butler, J. (2013). The role of IT in HE student retention. Education Journal, 2013(150), 5.

Cabrera, A. F., Deil-Amen, R., Prabhu, R., Terenzini, P. T., Chul, L., \& Franklin, R. E. Jr. (2006). Increasing the college preparedness of at-risk students. Journal of Latinos \& Education, 5, 79-97. http://dx.doi.org/10.1207/s1532771xjle0502_2

Cerezo, A., \& McWhirter, B. T. (2012). A brief intervention designed to improve social awareness and skills to improve Latino college student retention. College Student Journal, 46(4), 867-879.

Conner, J. O. (2009). Student engagement in an independent research project: The influence of cohort culture. Journal of Advanced Academics, 21, 8-38. http://dx.doi.org/10.1177/1932202X0902100102

Gibson, L. (2011). Student-Directed Learning: An Exercise in Student Engagement. College Teaching, 59(3), 95-101. http://dx.doi.org/10.1080/87567555.2010.550957

Hannum, W. H., Irvin, M. J., Lei, P., \& Farmer, T. W. (2008). Effectiveness of using learner-centered principles on student retention in distance education courses in rural schools. Distance Education, 29(3), 211-229. http://dx.doi.org/10.1080/01587910802395763 
Hawley, T. H., \& Harris, T. A. (2005). Student characteristics related to persistence for first year community college students. Journal of College Student Retention: Research, Theory and Practice, 7, 117-142. http://dx.doi.org/10.2190/E99D-V4NT-71VF-83DC

Heaton-Shrestha, C., May, S., \& Burke, L. (2009). Student retention in higher education: What role for virtual learning environments? Journal Of Further \& Higher Education, 33(1), 83-92. http://dx.doi.org/10.1080/03098770802645189

Huett, J. B., Kalinowski, K. E., Moller, L., \& Huett, K. C. (2008). Improving motivation and retention of online students through the use of ARCS-based e-mails. American Journal of Distance Education, 22, 159-176. http://dx.doi.org/10.1080/08923640802224451

Lillibridge, F. (2008). Retention tracking using institutional data. New Directions for Community Colleges, 143, 19-30. http://dx.doi.org/10.1002/cc.332

Mansfield, M., O’Leary, E., \& Webb, S. (2011). Retention in higher education: Faculty and student perceptions of retention programs and factors impacting attrition rates. M.Ed. Thesis, Indiana University South Bend, IN.

McPherson, J. L. (2008). The effects of retention strategies on student attrition at a private, four-year, religiously affiliated liberal arts university. Dissertation Abstracts International Section A, 68.

Nichols, M. (2010). Student perceptions of support services and the influence of targeted interventions on retention in distance education. Distance Education, 31(1), 93-113. http://dx.doi.org/10.1080/01587911003725048

Putsche, L., Storrs, D., Lewis, A. E., \& Haylett, J. (2008). The development of a mentoring program for university undergraduate women. Cambridge Journal of Education, 38(4), 513-528. http://dx.doi.org/10.1080/03057640802482322

Ramsey, J., \& Gorgol, L. (2010). Expanding access and opportunity: The Washington State Achievers Program. Washington, DC: Institute for Higher Education Policy.

Robinson, E., \& Niemer, L. (2010). A peer mentor tutor program for academic success in nursing. Nursing Education Perspectives, 31(5), 286-289.

Salazar, J. (2010). Educational technology.Staying Connected: Online education engagement and retention using educational techology tools. Clinical Laboratory Science, 23(3), 3-53.

Sanchez-Leguelinel, C. (2008). Supporting 'slumping' sophomores: Programmatic peer initiatives designed to enhance retention in the crucial second year of college. College Student Journal, 42(2), 637-646.

Schurr, K. T., Ruble, V., Palomba, C., \& Pickerill, B. (1997). Relationships between the MBTI and selected aspects of Tinto's model for college attrition. Journal of Psychological Type, 40, 31-42.

Smith, B. J. (2010). The influence of a new student introduction program on freshman student retention at a rural, two-year community college. ProQuest LLC.

Smyth, J. (2006). 'When students have power': Student engagement, student voice, and the possibilities for school reform around 'dropping out' of school. International Journal of Leadership in Education, 9(4), 285-298. http://dx.doi.org/10.1080/13603120600894232

Starke, M. C., Harth, M., \& Sirianni, F. (2001). Retention, bonding, and academic achievement: Success of a first year seminar. Journal of the First Year Experience \& Students in Transition, 13, 7-35.

Taylor, R. (2005). Creating a connection: Tackling student attrition through curriculum development. Journal Of Further \& Higher Education, 29(4), 367-374. http://dx.doi.org/10.1080/03098770500353698

Terenzini, P. T., Springer, L., Yaeger, P. M., Pascarella, E. T., \& Nora, A. (1996). First-generation college students: Characteristics, experiences, and cognitive development. Research in Higher Education, 37, 1-22. http://dx.doi.org/10.1007/BF01680039

Thelin, J. R., \& American Enterprise Institute for Public Policy Research. (2010). The attrition tradition in American higher education: Connecting past and present. Working Paper 2010-01. Washington, DC: American Enterprise Institute for Public Policy Research.

Valentine, J. C., Hirschy, A. S., Bremer, C. D., Novillo, W., Castellano, M., \& Banister, A. (2009). Systematic reviews of research: Postsecondary transitions. Identifying effective models and practices. Louisville, KY: National Research Center for Career and Technical Education. 
Willcoxson, L., Cotter, J., \& Joy, S. (2011). Beyond the first year experience: The impact on attrition of student experiences throughout undergraduate degree studies in six diverse universities. Studies in Higher Education, 36, 331-352. http://dx.doi.org/10.1080/03075070903581533

\section{Appendix}

Commonwealth funded Higher Education Participation and Partnership Program (HEPPP) projects concerned with identifying and affecting attrition rates of under-prepared students

\begin{tabular}{|c|c|c|}
\hline Intervention type & Deakin University & Southern Cross University \\
\hline HEPPP Committee & $\begin{array}{l}\text { Diverse Student Cohort Tracking } \\
\text { Committee (DSCTC). Responsible for the } \\
\text { implementation of HEPPP projects (known } \\
\text { as Deakin University Participation and } \\
\text { Partnership Program (DUPPP) at Deakin). }\end{array}$ & $\begin{array}{l}\text { i-OnTrack Committee. Responsible for the } \\
\text { implementation of HEPPP projects. }\end{array}$ \\
\hline \multirow[t]{2}{*}{ Technology } & $\begin{array}{l}\text { Deakin at Your Doorstep. Online courses } \\
\text { accessible via local regional community } \\
\text { centre or Technical and Further Education } \\
\text { (TAFE) college at a time that suits them, to } \\
\text { meet with other students and to create their } \\
\text { own study groups. }\end{array}$ & $\begin{array}{l}\text { i-Ontrack project. A diagnostic tool that } \\
\text { will endeavour to distinguish those } \\
\text { students likely to be most 'at-risk' of } \\
\text { withdrawal or failure based on LMS } \\
\text { activity usage. In addition, other data such } \\
\text { as low SES background, parent's education } \\
\text { etc. will be used as an indicator of 'at-risk'. }\end{array}$ \\
\hline & $\begin{array}{l}\text { PASS (Peer Assisted Study Session). An } \\
\text { e-live virtual student engagement tool. } \\
\text { Therefore the off-campus students can take } \\
\text { part. Also utilised by 'Deakin at your } \\
\text { Doorstep' to provides access to on-line } \\
\text { courses from remote locations. }\end{array}$ & \\
\hline \multirow[t]{4}{*}{ Support } & $\begin{array}{l}\text { Succeed At Deakin. Deakin University is } \\
\text { utilising five triggers such as not attending } \\
\text { orientation, not attending tutorials, not } \\
\text { logging into the LMS (Blackboard), not } \\
\text { submitting the first assessment task etc. } \\
\text { Each of these activates an intervention } \\
\text { which may be a contact through a text } \\
\text { message, a telephone call, an email, with } \\
\text { the aim at prompting students to take up } \\
\text { support. }\end{array}$ & $\begin{array}{l}\text { Peer-mentoring. SCU's School of Arts and } \\
\text { Social Sciences is developing a peer } \\
\text { mentoring program based on experiences } \\
\text { of final year students which best enabled } \\
\text { them to progress through their course and } \\
\text { the barriers they encountered and } \\
\text { presumably overcame. These experiences } \\
\text { are then passed onto first year mentees. }\end{array}$ \\
\hline & $\begin{array}{l}\text { Peer-mentoring. This involves senior } \\
\text { students supporting small groups of new } \\
\text { students for six weeks with no expectation } \\
\text { beyond that. However, communication } \\
\text { between mentors and mentees often } \\
\text { continues beyond the six weeks. }\end{array}$ & \\
\hline & $\begin{array}{l}\text { Curricula embedding. To combat a lack of } \\
\text { 'referencing' skills amongst Deakin } \\
\text { students, academic skills are embedded into } \\
\text { the standard first year curriculum across all } \\
\text { courses. This is designed to assist } \\
\text { under-prepared students with necessary } \\
\text { skills. }\end{array}$ & \\
\hline & $\begin{array}{l}\text { The 'drop-in' program. Mentors are } \\
\text { available in a physical space at particular } \\
\text { times and new students can ask whatever }\end{array}$ & \\
\hline
\end{tabular}




\begin{tabular}{|c|c|c|}
\hline & $\begin{array}{l}\text { 'stupid' questions they like. Mentors refer } \\
\text { difficult questions to the relevant student } \\
\text { support services. }\end{array}$ & \\
\hline \multirow[t]{2}{*}{ Unpreparedness } & $\begin{array}{l}\text { Melbourne Institute of Business and } \\
\text { Technology (MIBT).Deakin University has } \\
\text { an articulation arrangement with the MIBT } \\
\text { whereby students commence studies with } \\
\text { the private provider and obtain credit for } \\
\text { studies undertaken towards a business } \\
\text { degree. Initially international students } \\
\text { utilised this arrangement. But now low SES } \\
\text { students or other underprepared students are } \\
\text { seeing this as a viable pathway to a degree } \\
\text { at Deakin. }\end{array}$ & $\begin{array}{l}\text { Preparation for Success. An alternative } \\
\text { pathway to undergraduate courses. } \\
\text { 'Preparation for Success' is an enabling } \\
\text { course that provides basic study skills as } \\
\text { well as developing research and writing } \\
\text { skills in the arts and business or the } \\
\text { sciences. }\end{array}$ \\
\hline & $\begin{array}{l}\text { Articulation arrangements. In addition to } \\
\text { the MIBT pathway, there are articulation } \\
\text { arrangements between Deakin and a } \\
\text { number of TAFE Colleges in Victoria. } \\
\text { Deakin is also exploring ways to assist } \\
\text { those students struggling at university to } \\
\text { return to the TAFE system. }\end{array}$ & $\begin{array}{l}\text { Articulation arrangements. SCU offers } \\
\text { two-year Associate Degrees in Allied } \\
\text { Health, Arts and Business for students who } \\
\text { could not meet entry requirements to } \\
\text { bachelor degrees. Students complete a } \\
\text { TAFE Certificate IV as part of the first year } \\
\text { of the Allied Health and Arts courses thus } \\
\text { providing a range of exit points if students } \\
\text { do not choose to go onto undergraduate } \\
\text { studies. }\end{array}$ \\
\hline \multirow[t]{2}{*}{ Future Students } & $\begin{array}{l}\text { u.life. A Deakin pilot program which targets } \\
\text { Year } 9 \text { students and aims to demystify } \\
\text { university and study. }\end{array}$ & $\begin{array}{l}\text { Unibound Outreach program. One of a } \\
\text { number of pre-tertiary orientation } \\
\text { programs designed to change aspirations in } \\
\text { year } 7-9 \text { students enrolled at } 15 \text { schools. Ie. } \\
\text { Indigenous professors speaking to } \\
\text { indigenous students about their success at } \\
\text { university. }\end{array}$ \\
\hline & $\begin{array}{l}\text { Widening Horizons. A program which was } \\
\text { designed to build on the u.life program by } \\
\text { opening up different pathways for students } \\
\text { who are young parents. }\end{array}$ & $\begin{array}{l}\text { Head Start Scheme. Aims to enrol the 'best } \\
\text { and brightest' local school children in } \\
\text { university units through and providing } \\
\text { credit for those units when they are } \\
\text { admitted to an SCU undergraduate course. }\end{array}$ \\
\hline
\end{tabular}

\section{Copyrights}

Copyright for this article is retained by the author(s), with first publication rights granted to the journal.

This is an open-access article distributed under the terms and conditions of the Creative Commons Attribution license (http://creativecommons.org/licenses/by/3.0/). 